\title{
Supplemented zinc does not alter mood in healthy older European adults - a randomised placebo-controlled trial: the Zenith study
}

\author{
Barbara J Stewart-Knox ${ }^{1, *}$, Gordon Rae ${ }^{2}$, Ellen EA Simpson ${ }^{2}$, Chris McConville ${ }^{2}$, Jacqueline \\ $\mathrm{O}^{\prime}$ Connor ${ }^{1}$, Angela Polito ${ }^{3}$, Maud Andriollo-Sanchez ${ }^{4}$, Charles Coudray ${ }^{5}$ and JJ Strain ${ }^{1}$ \\ ${ }^{1}$ Northern Ireland Centre for Food and Health, University of Ulster, Coleraine, BT52 1SA, Northern Ireland, UK: \\ ${ }^{2}$ Psychology Research Institute, University of Ulster, Coleraine, Northern Ireland, UK: ${ }^{3}$ National Research Institute \\ on Food and Nutrition, Department of Nutritional Science, Rome, Roma, Italy: ${ }^{4}$ Faculté de Pharmacie, \\ Laboratoire de Biologie de Stress Oxydant, Nutrition Vieillissement et Maladies Cardiovasculaires, University de \\ Joseph Fourier, Grenoble, France: ${ }^{5}$ Unité des Maladies Métaboliques et Micronutrients, INRA, Centre de \\ Recherche en Nutrition Humaine d'Auvergne, Clermont-Ferrand/Theix, France
}

\section{Submitted 23 October 2009: Accepted 30 August 2010: First published online 28 January 2011}

\begin{abstract}
Objective: Older people are vulnerable to zinc deficiency, which may impact upon their mood. This randomised, placebo-controlled, double-blind intervention study aimed to investigate the effect of oral zinc gluconate supplementation $(15 \mathrm{mg} / \mathrm{d} ; 30 \mathrm{mg} / \mathrm{d}$; and placebo) on subjective mood (affect) in older Europeans. Subjects: Healthy volunteers ( $n$ 387) aged $55-87$ years were recruited.

Setting: Volunteers in Rome (Italy; $n$ 108) and Grenoble (France; $n$ 91) were aged 70-87 years and those in Coleraine (Northern Ireland; $n$ 93) and Clermont-Ferrand (France; $n$ 95) were aged $55-70$ years.

Design: Mood was measured using the Positive and Negative Affect Scale on four occasions per day over $4 \mathrm{~d}$ at baseline, 3 and 6 months post-intervention.

Results: Mixed ANOVA indicated that neither positive nor negative affect altered in response to zinc $(15 \mathrm{mg} / \mathrm{d}$ or $30 \mathrm{mg} / \mathrm{d}$ ) compared to placebo in either the $55-70$ years or the $\geq 70$ years age group.

Conclusions: These results suggest that zinc does not benefit mood in healthy older people.
\end{abstract}

Psychological well-being is high on the list of public health policy priorities, with the emphasis on prevention ${ }^{(1)}$. Zinc is an essential trace element ${ }^{(2)}$ that is present in large quantities in the brain and may be important for the maintenance of psychological well-being. Zinc-containing neurons are found in the forebrain interconnecting the cerebral cortex (the cognitive or 'thinking' part of the brain) and the limbic system (the affective or 'feeling' part of the brain) ${ }^{(3)}$. The synaptic vesicles of the hippocampus and amygdala, which are both limbic structures, contain particularly large quantities of zinc ${ }^{(4)}$, implying a role for zinc in the control of emotion. Zinc-containing neurons are receptive to glutamine, an amino acid neurotransmitter that is excitatory and that exerts a neuromodulatory effect on post-synaptic glutamate receptors within the hypothalamic-pituitary-adrenal axis (HPA) system ${ }^{(4,5)}$. Rodent studies have indicated that this action occurs mainly through the hippocampus synapses, which are involved in the regulation of the HPA system ${ }^{(6-11)}$. Zinc may also be involved in the control of the serotonergic system ${ }^{(5,12,13)}$. Zinc has been shown to increase the density of 5-HT serotonin receptors in the hippocampus and frontal cortex in rats ${ }^{(12)}$. Post-mortem evidence suggests that zinc may have a role in the nutritional methylation processes $^{(14)}$ that are also believed to be important in the regulation of $\operatorname{mood}^{(15)}$. The human central nervous system appears to be adversely affected by zinc deficiency. Lower serum zinc is associated with depression ${ }^{(16-20)}$ and a marker of treatment resistance in clinical depression ${ }^{(20,21)}$. Lower serum zinc is also associated with disordered behaviour $^{(22-24)}$. Zinc supplementation has also been shown to ameliorate depression in clinical groups ${ }^{(25,26)}$. There is an apparent dearth of human studies of zinc and well-being in healthy (non-clinical) groups. Among the few studies of healthy individuals is a recent cross-sectional study of Korean women ( $n$ 570), which indicated that among other nutrients and trace elements, lower dietary zinc intake was associated with higher stress scores on the short version of the Psychological Well-being Index ${ }^{(27)}$. A recent doubleblind, placebo-controlled trial of zinc $(7 \mathrm{mg} / \mathrm{d})$ in young women ( $n$ 30) found reduced scores on the anger/hostility and depression scales of the Profile of Mood States ${ }^{(28)}$. These studies imply a link between zinc and psychological well-being in health. There appear to be no existing trials of zinc and well-being or mood in men and/or older people. 
Europe and much of the industrialised Western world has a growing ageing population ${ }^{(1)}$, hence, the need to maintain psychological well-being and quality of life in this vulnerable age group. The elderly are particularly at risk of zinc deficiency, the likelihood of which increases with age ${ }^{(29-33)}$ as a result of a range of physiological, social, psychological and economic factors ${ }^{(34)}$ that may be associated with the decreased consumption of zinc-rich foods ${ }^{(35-38)}$. Dysregulation of the HPA system is associated with the increased risk of CVD, diabetes, cancer, inflammatory conditions and neurodegenerative disorders ${ }^{(39)}$. HPA system activity has been shown previously to be related to positive affect (PA) in the elderly ${ }^{(40)}$. Maintaining a higher PA in old age, therefore, is potentially important for general health and well-being as well as disease prevention $^{(41)}$ in otherwise healthy older people. Assuming that zinc exerts a neuromodulatory effect through the HPA system, optimising zinc status in older people, therefore, is likely to have far-reaching benefits to psychological health. Yet, there do not appear to be any previous studies that have considered zinc and affect in healthy older individuals. Existing evidence for benefits of zinc to psychological well-being is mainly derived from post hoc investigation using psychiatric in-patients. Trials in healthy populations are necessary to further our understanding of how dietary constituents such as zinc impact upon health and well-being and to provide evidence to support or refute potential functional claims for zinc-rich food products. Trials in healthy individuals are especially important, given the widespread and increasing use of self-prescribed nutrient supplements by the older public ${ }^{(42)}$. The Zenith Study aimed to assess the effects of zinc supplementation in the normal healthy older population. It was necessary, therefore, to intervene with zinc at dosages that would be available for purchase over the counter without prescription. This randomised, placebo-controlled, double-blind intervention study reports the effect upon PA and negative affect (NA) of zinc $(15 \mathrm{mg} / \mathrm{d}$ and $30 \mathrm{mg} / \mathrm{d})$ supplements administered orally over 6 months compared to placebo in healthy 55-70-year-olds recruited to the Zenith Study in Coleraine and Clermont-Ferrand and $\geq 70$-year-olds in Grenoble and Rome. This research meets an imperative for controlled supplementation trials investigating the effect of zinc on psychological well-being in the older population. It is hypothesised that zinc supplementation will alter subjective affective state compared to placebo.

\section{Methods}

The Zenith Study was a randomised, double-blind, placebo-controlled intervention trial of zinc in older adults, which was conducted in four European centres. Ethics approval for the study was obtained from recognised research centres in each country. Informed, written consent was obtained from each participant.

\section{Sampling}

Volunteers were outreached in different ways including through local television and radio broadcast, posters and through leaflets distributed in supermarkets, clubs that free-living elderly people frequently visit, health centres, and family doctors. Prospective volunteers then initiated contact with the research group who then arranged an appointment for the preliminary screening. The volunteers were screened first by clinical examination, anthropometry, smoking and alcohol consumption, cognitive impairment, depression and biochemistry profiles. Those selected for inclusion in the study were apparently healthy, not morbidly obese and with a BMI of between $20 \mathrm{~kg} / \mathrm{m}^{2}$ and $30 \mathrm{~kg} / \mathrm{m}^{2(43)}$. Only those who had no evidence of dementia, as indicated by a score $>23$ in the Mini Mental State Examination (MMSE) test ${ }^{(44)}$, were included. Volunteers were screened for depression using the Geriatric Depression Scale (GDS) ${ }^{(45)}$. The GDS has been validated as a screening tool for depression against the DSM-IV criteria according to which only those scoring $\geq 6$ can be considered not clinically depressed ${ }^{(46)}$. Those with a score of $\leq 5$ were included. Participants were also excluded if they had a positive serology for HIV or hepatitis C, if they smoked more than ten cigarettes per day; consumed alcohol $>30 \mathrm{~g} / \mathrm{d}$ for men and $>20 \mathrm{~g} / \mathrm{d}$ for women; had unusual dietary habits (vegetarianism and veganism); used a mineral supplement in the 3 months preceding the study; used more than three drugs daily if aged 55-70 years; used more than four drugs daily if over 70 years; used drugs including antidepressants, laxatives and hormone replacement therapy; or had a pathological disease (cancer, diabetes, insufficient renal or hepatic performance, malabsorption and inflammatory chronic pathologies). Complete details about screening and recruitment processes have been described previously by Polito et al. ${ }^{(47)}$.

\section{Serum zinc}

Unfortunately, there is no single accurate measure of zinc status ${ }^{(48,49)}$. For the purpose of the present study, serum zinc was taken as a putative indicator of current zinc status $^{(50)}$. Fasting blood samples were obtained for the zinc assay in the morning. Blood samples for the zinc assay were collected via venepuncture by qualified the phlebotomists, using trace element-free Vacutainer ${ }^{\circledR}$ tubes (Becton, Dickinson and company Ltd, Oxford, UK). The blood sample was taken in the morning after a $12 \mathrm{~h}$ fast by the participants. Immediately after drawing, the blood samples were kept on ice, and then centrifuged at $1000 \mathrm{~g}$ for $15 \mathrm{~min}$ at $4^{\circ} \mathrm{C}$. Serum zinc was immediately isolated, aliquoted and stored at $-80^{\circ} \mathrm{C}$. Serum zinc concentrations at baseline were determined at INRA Clermont-Ferrand, France, by flame atomic absorption spectrometry using a Perkin-Elmer 560 instrument (Perkin Elmer, Cambridge, UK) ${ }^{(50)}$. Internal quality control was checked using Seronorm ${ }^{\circledR}$ trace element serum (Sero ${ }^{\circledR}$, Billingstad, Norway). 


\section{Dietary zinc}

Dietary zinc intake was assessed at baseline by means of a semi-structured standardised $4 \mathrm{~d}$ food diary over two weekdays and two weekend days consecutively, which included estimates of portion size, the brand name of the product and/or the recipe if cooked from fresh. The information in the food diaries was analysed using the NetWISP version 3.0 (Tinuviel Software Anglesey, UK) database. A full account of the dietary assessment procedure has been provided previously by Polito et $a l^{(51)}$.

\section{Positive and Negative Affect Scale}

The Positive and Negative Affect Schedule (PANAS) is a well-validated twenty-item self-reported psychometric measure of subjective mood developed by Watson et al. ${ }^{(52)}$. Watson and Tellegen ${ }^{(53)}$ proposed that there are two distinct dimensions of mood state, PA and NA, which together account for over two-thirds of the variance in mood. PA is associated with feelings of alertness, enthusiasm and happiness and NA with displeasure and dissatisfaction ${ }^{(54)}$. PANAS scores have been shown to correlate with salivary cortisol levels ${ }^{(40)}$ and whole blood serotonin levels in healthy individuals ${ }^{(55,56)}$. The scales have been found to have high internal consistency, with Cronbach's $\alpha$ ranging from 0.84 to 0.87 for the NA scale and 0.84 to 0.90 for the PA scale ${ }^{(57)}$. Repeated measures of affect were taken during the week before the centre visit, including one further measure taken on the morning of testing. The participants were asked to complete four self-reported PANAS questionnaires daily (on rising, after lunch, after dinner, and before going to bed) for four consecutive days at baseline, 3 and 6 months. The scale took approximately 2 min to complete. The items were: interested; distressed; excited; upset; strong; guilty; scared; hostile; enthusiastic; proud; irritable; alert; ashamed; inspired; nervous; determined; attentive; jittery; active; and afraid. Responses to the PANAS were recorded on a 5-point Likert scale ranging from 'not at all' $=1$ to 'extremely' $=5$. A score for each scale was obtained by summing item scores.

\section{Intervention}

Eligible volunteers were randomly assigned to three groups to receive either $15 \mathrm{mg} / \mathrm{d}$ or $30 \mathrm{mg} / \mathrm{d}$ zinc gluconate or placebo orally. Zinc capsules were issued in dated pillboxes at baseline and at 3 and 6 months into the supplementation phase. The participants were instructed to swallow the capsules with breakfast. The degree of compliance was estimated by collecting the number of returned capsules at 3 and 6 months. Compliance was tested and was found to be $>98 \%$ for all groups.

\section{Data analysis}

The mood data were analysed using a mixed ANOVA. Separate analyses were computed for the 55-70-year-olds ( $n$ 188; from Coleraine and Clermont-Ferrand) and for the $\geq 70$-year-olds ( $n$ 199; from Grenoble and Rome). There were three between-group factors (sex, centre and treatment) and one repeated measure (baseline, 3 and 6 months post-intervention) included in each ANOVA. Mean PA and NA were treated as separate dependent variables, which also required separate ANOVAs. In the absence of relevant previous studies in this area, a conservative value of $f^{2}=0 \cdot 025$ for effect sizes was adopted. For the mood scale it was assumed that the correlations among each of the repeated measures were 0.42 (taken from the PANAS manual). Power calculations were performed using GPOWER general power analysis computer program (G*Power, Bonn, Germany) ${ }^{(58)}$. With $\alpha=0 \cdot 05$ and assuming 180 participants within each age group (55-70 and $\geq 70$ years), the power values for the between-groups and within-groups and interaction effects were $0.36,0.99$ and $0 \cdot 81$, respectively. As the interaction effects (particularly the treatment-time interaction) were of prime concern in the present study, the sample sizes for both the younger ( $n$ 188) and the older ( $n$ 199) age groups were regarded as satisfactory. Significance was set at $P<0 \cdot 05$. The Statistical Package for Social Sciences statistical software package version 11.5 (SPSS UK Ltd., Feltham, UK) was used for statistical analysis.

\section{Results}

Approximately $10-15 \%$ of those who initiated contact were included in the study. Equal proportions of healthy male and female older volunteers were recruited from four European centres. Coleraine, Northern Ireland ( $n$ 93) and Clermont-Ferrand, France ( $n$ 95) recruited participants aged 55-70 years, while Rome, Italy ( $n$ 108) and Grenoble, France ( $n$ 91) recruited participants who were $>70$ years of age. In total, 387 participants successfully completed the trial (Table 1). A full description of the sample characteristics has been provided elsewhere by Simpson et al. ${ }^{(59)}$.

\section{Baseline measures}

Neither sex nor age differed between the treatment groups. The younger (55-70 years) age group comprised a higher proportion $(84 \%)$ of professional occupations than the older ( $\geq 70$ years) age group (68\%). A higher proportion of those in the younger age group (96\%) than the older age group (35\%) were educated to the tertiary level. Neither social class nor educational level differed between the treatment groups. There were no apparent differences by age group or treatment group in dietary zinc intake at baseline. There were no differences in MMSE or (GDS) scores by age group or treatment condition ${ }^{(60)}$.

\section{Serum zinc}

Mean serum zinc was within the normal range $(11-18 \mu \mathrm{mol} / \mathrm{l})^{(61)}$ for the placebo $($ mean $=13 \cdot 20 \quad(\mathrm{SD}$ $1 \cdot 69) \mu \mathrm{mol} / \mathrm{l}), 15 \mathrm{mg}(\mathrm{mean}=13 \cdot 28(\mathrm{sD} 1 \cdot 84) \mu \mathrm{mol} / \mathrm{l})$ and $30 \mathrm{mg} \quad($ mean $=13 \cdot 13 \quad(\mathrm{sD} 1 \cdot 63) \mu \mathrm{mol} / \mathrm{l}) \quad$ supplemented 
Table 1 Sociodemographic variables for each region, given as percentages

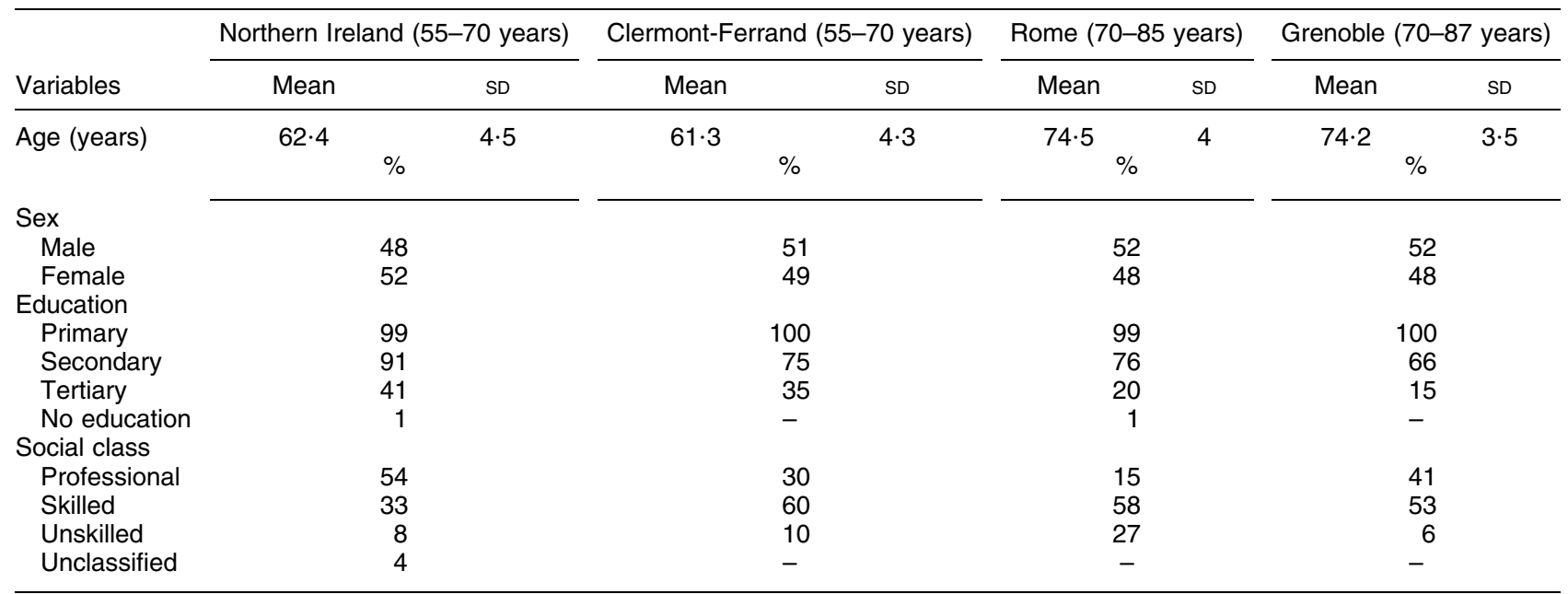

Total participants=387: Northern Ireland =93; Clermont-Ferrand =95; Rome =108; and Grenoble $=91$.

Table 2 PANAS scores for each treatment group (55-70-year-olds/Coleraine and Clermont-Ferrand) over time ( $n$ 188)

\begin{tabular}{|c|c|c|c|c|c|c|c|c|c|c|c|c|}
\hline & \multicolumn{6}{|c|}{ Positive affect } & \multicolumn{6}{|c|}{ Negative affect } \\
\hline & \multicolumn{2}{|c|}{ Placebo } & \multicolumn{2}{|c|}{$\mathrm{Zn}(15 \mathrm{mg})$} & \multicolumn{2}{|c|}{$\mathrm{Zn}(30 \mathrm{mg})$} & \multicolumn{2}{|c|}{ Placebo } & \multicolumn{2}{|c|}{$\mathrm{Zn}(15 \mathrm{mg})$} & \multicolumn{2}{|c|}{$\mathrm{Zn}(30 \mathrm{mg})$} \\
\hline & Mean & SD & Mean & SD & Mean & SD & Mean & SD & Mean & SD & Mean & SD \\
\hline Baseline & $26 \cdot 14$ & $4 \cdot 83$ & $28 \cdot 05$ & $5 \cdot 49$ & $28 \cdot 40$ & $5 \cdot 70$ & $11 \cdot 66$ & $2 \cdot 63$ & $11 \cdot 72$ & $2 \cdot 11$ & $11 \cdot 44$ & $2 \cdot 00$ \\
\hline 3 months & $27 \cdot 05$ & $4 \cdot 21$ & $28 \cdot 59$ & $5 \cdot 85$ & $29 \cdot 47$ & $5 \cdot 76$ & $11 \cdot 92$ & $2 \cdot 70$ & $12 \cdot 24$ & 3.67 & $11 \cdot 46$ & 1.99 \\
\hline 6 months & $26 \cdot 86$ & $5 \cdot 20$ & $28 \cdot 70$ & 6.09 & $29 \cdot 06$ & $5 \cdot 54$ & $11 \cdot 84$ & $2 \cdot 89$ & $12 \cdot 22$ & $3 \cdot 30$ & $11 \cdot 22$ & 1.95 \\
\hline
\end{tabular}

PANAS, Positive and Negative Affect Score.

groups at baseline and remained so throughout the intervention period. Serum zinc increased over time $(F(4197)=$ $11 \cdot 021, P=0.000)$ in both the $15 \mathrm{mg}$ (mean $=13.99$ (SD $2 \cdot 47) \mu \mathrm{mol} / \mathrm{l} ; P=0 \cdot 018)$ and $30 \mathrm{mg}($ mean $=15 \cdot 03$ (sD 3.17) $\mu \mathrm{mol} / \mathrm{l} ; \quad P=0 \cdot 000)$ supplemented groups compared to placebo $($ mean $=13.05(\mathrm{sD} 1.66) \mu \mathrm{mol} / \mathrm{l})$ suggesting compliance with the intervention. Serum zinc concentrations in response to zinc $(30 \mathrm{mg})$ were higher among those recruited in Rome $($ mean $=16 \cdot 26(\mathrm{sD} 3 \cdot 41) \mu \mathrm{mol} / \mathrm{l})$ than Grenoble $($ mean $=13 \cdot 64(\mathrm{SD} 2 \cdot 21) \mu \mathrm{mol} / \mathrm{l})$ post-intervention $(F(4197)=$ 3.526, $P=0 \cdot 008)$.

\section{Affect (the Positive and Negative Affect Scale) and zinc}

There were no treatment $(15 \mathrm{mg} / \mathrm{d}$ zinc; $30 \mathrm{mg} / \mathrm{d}$ zinc; or placebo) $\times$ time (baseline; 3 months; or 6 months postintervention) or interaction effects, indicating that the treatment had no differential effects on affect (PANAS) over time. For NA among the 55-70-year-olds, the interaction effect was $F(4340)=1 \cdot 56, P=0 \cdot 185$ (Table 1) and for the $\geq 70$-year-olds, $F(4372)=0 \cdot 466, P=0 \cdot 761$ (Table 2 ). Interaction effects for PA among the 55-70-year-olds were $F(4340)=0 \cdot 37, P=0.833$ (Table 2) and among the $\geq 70$-year-olds were $F(4372)=1 \cdot 32, P=0 \cdot 261$ (Table 3). None of the triple interaction effects involving treatment and time were significant.

\section{Centre and affect (the Positive and Negative Affect Scale)}

There was a significant treatment $\times$ centre interaction effect for NA among the $\geq 70$-year age group $(F(1186)=3 \cdot 73$, $P=0 \cdot 025)$. For the placebo, $15 \mathrm{mg} / \mathrm{d}$ and $30 \mathrm{mg} / \mathrm{d}$ treatment groups, the means were $11.45,13.43$ and 11.94 , respectively, for Rome and 13.06, 12.83 and 14.38, respectively, for Grenoble. For Grenoble, the trend for NA was U-shaped showing a decrease at 3 months into the intervention and returning to baseline at 6 months. For Rome, the trend for NA was an inverted U-shape such that NA was increased at 3 months into the intervention and returning to baseline at 6 months. There were no significant interactions between treatment and centre for PA in either the 55-70-year or $\geq 70$-year age group.

\section{Gender and affect (the Positive and Negative Affect Scale)}

With the exception of a significant gender $\times$ centre interaction effect for NA among the 55-70-year-olds $(F(1170)=4 \cdot 71, P=0 \cdot 031)$, there were no significant main effects or interaction effects for gender. The significant gender $\times$ centre interaction effect was such that male volunteers reported higher NA than female volunteers in the Coleraine sample (mean $=12 \cdot 00$ and $11 \cdot 39$, 
Table 3 PANAS scores for each treatment group ( $\geq 70$-year-olds/Rome and Grenoble) over time ( $n$ 199)

\begin{tabular}{|c|c|c|c|c|c|c|c|c|c|c|c|c|}
\hline & \multicolumn{6}{|c|}{ Positive affect } & \multicolumn{6}{|c|}{ Negative affect } \\
\hline & \multicolumn{2}{|c|}{ Placebo } & \multicolumn{2}{|c|}{$\mathrm{Zn}(15 \mathrm{mg})$} & \multicolumn{2}{|c|}{$\mathrm{Zn}(30 \mathrm{mg})$} & \multicolumn{2}{|c|}{ Placebo } & \multicolumn{2}{|c|}{$\mathrm{Zn}(15 \mathrm{mg})$} & \multicolumn{2}{|c|}{$\mathrm{Zn}(30 \mathrm{mg})$} \\
\hline & Mean & SD & Mean & SD & Mean & SD & Mean & SD & Mean & SD & Mean & SD \\
\hline Baseline & $22 \cdot 54$ & $8 \cdot 23$ & $22 \cdot 74$ & $6 \cdot 78$ & $23 \cdot 25$ & $7 \cdot 86$ & $11 \cdot 96$ & $2 \cdot 74$ & $12 \cdot 96$ & 3.72 & 13.05 & $4 \cdot 0$ \\
\hline 3 months & 24.59 & 8.65 & $23 \cdot 78$ & $5 \cdot 96$ & 23.59 & $7 \cdot 62$ & $12 \cdot 25$ & $3 \cdot 21$ & $13 \cdot 22$ & 3.72 & $13 \cdot 41$ & $4 \cdot 42$ \\
\hline 6 months & $24 \cdot 36$ & 9.02 & $23 \cdot 20$ & $6 \cdot 50$ & 23.59 & $7 \cdot 68$ & $12 \cdot 29$ & 3.02 & $13 \cdot 27$ & $4 \cdot 90$ & $12 \cdot 81$ & $4 \cdot 26$ \\
\hline
\end{tabular}

PANAS, Positive and Negative Affect Score.

respectively), whereas the reverse was true in the ClermontFerrand sample $($ mean $=11 \cdot 48$ and $12 \cdot 14)$.

\section{Discussion}

Studies of clinically depressed ${ }^{(18-24)}$ and healthy ${ }^{(27,28)}$ groups have suggested a link between zinc status and psychological well-being. Given evidence to suggest that for a multiplicity of reasons, ageing can be associated with zinc depletion ${ }^{(31)}$, it was hypothesised that supplemented zinc would enhance mood in older people. It was, therefore, surprising to find no alteration in PA or NA in response to zinc $(15 \mathrm{mg} / \mathrm{d}$ or $30 \mathrm{mg} / \mathrm{d})$ compared to placebo in either the younger (55-70 years) or the older ( $\geq 70$ years) age group, who had lower PA than the younger age group at baseline ${ }^{(61)}$. Both NA and PA were unaffected by zinc supplementation in either age group. In the older age group ( $\geq 70$ years), NA increased among those in Rome and decreased among those in Grenoble 3 months into the intervention and returned to baseline in both groups at 6 months. This trend is difficult to explain. Although serum zinc was higher among those in Rome than Grenoble at 3 months, serum zinc is not an accurate indicator of zinc status and could have been altered in response to a range of factors unrelated to affect ${ }^{(49)}$. Increased serum zinc concentrations post-treatment, however, suggest good compliance with the intervention in both groups. The PANAS is a well-validated subjective (self-reported) psychometric measure of affect ${ }^{(52)}$, which has been widely used and previously used in other studies involving elderly adults ${ }^{(62)}$. The PANAS has also been shown to correlate with the biochemical markers of affect $^{(40,55,56)}$. This correlation indicates that although the scales measure subjective affect, the data generated can be considered sensitive to corresponding changes in neurochemical activity. The PANAS can, therefore, be assumed to have good concurrent validity for the measurement of affect. Although the PA data collected for the present study agree with those of the established norms, the NA scores appear to be less than those suggested by established norms for older people ${ }^{(52)}$. The relatively low NA reported by our sample at baseline may explain the lack of change in NA following zinc supplementation. The apparent lack of change in affect in response to zinc could also be because the participants were zinc replete ${ }^{(50)}$. Screening procedures were stringent and care was taken to recruit only physically and psychologically healthy older people to the Zenith Study. Health and well-being tend to be confounded with social factors. It is possible that in selecting only healthy individuals, those from socio-economically deprived segments of society have been excluded. That our sample was biased towards the higher social classes and those who had spent a relatively longer period in education (Table 1) may also explain the apparently good psychological well-being among our sample and lack of response to the intervention. The participants, by virtue of having volunteered, may not be entirely representative of the general population, potentially limiting the degree to which the findings can be extrapolated to the general older population. Those who have spent longer periods of time in education and those in more privileged social classes tend to have lower mortality and morbidity ${ }^{(1)}$ and may, therefore, also have a greater chance of being recruited to such studies.

\section{Conclusion}

The present study seems to be the first randomised, double-blind, placebo-controlled intervention trial investigating the impact of supplemented zinc upon affect in healthy older adults. Intervention outcomes were assessed using the PANAS, which is a well-validated subjective (self-reported) psychometric measure of affect. The study was also strong in that it used a relatively large sample comprising late middle-aged and elderly individuals from both northern and southern European populations with adequate power with which to uphold the null hypothesis and within which sex and cultural effects were controlled. These data suggest that zinc supplementation at considered $15 \mathrm{mg} / \mathrm{d}$ or $30 \mathrm{mg} / \mathrm{d}$ does not alter mood in healthy elderly European adults.

\section{Acknowledgements}

The project was funded by the European Commission 'Quality of Life and Management of Living Resources' Fifth Framework Programme, Contract no. QLK1-CT2001-00168. The authors have no conflicts of interest. 
B.J.S.-K. contributed to the design of the study and drafted the paper; G.R. undertook the statistical analysis; E.E.A.S. undertook data collection and database development; J.M.O. coordinated research at University of Ulster; C.Mc.C. contributed to the mood protocol; A.P. supervised the data collection at INRAN; M.A.-S. supervised the data collection at Grenoble; C.C. supervised the data collection at INRA and coordinated Zenith; and J.J.S. contributed to the nutritional protocol and advised on the zinc intervention.

\section{References}

1. Wanless D (2004) Securing Good Health for the Whole Population: Final Report. London: HM Treasury; available at http://www.hmtreasury.gov.uk/consultations and legislation/wanless/consultwanless04final.cfm

2. Hambidge M (2000) Human zinc deficiency. J Nutr 130, 5S Suppl., 1344S-1349S.

3. Frederickson CJ, Won Suh S, Silva D et al. (2000) Importance of zinc in the central nervous system: the zinc-containing neuron. J Nutr 130, 5S Suppl., 1471S-1483S.

4. Colvin RA, Davis N, Nipper RW et al. (2000) Zinc transport in the brain: routes of zinc influx and efflux in neurons. J Nutr 130, 5 S Suppl., 1484S-1487S.

5. Szewczyk B, Poleszak E, Wlaz P et al. (2009) The involvement of the serotonergic system in the antidepressant effect of zinc in the forced swim test. Prog Neuropsychopharmacol Biol Psychiatry 33, 323-329.

6. Matias CM, Saggau P \& Quinta-Ferreira ME (2010) Blockade of presynaptic K ATP channels reduces the zinc-mediated posttetanic depression at hippocampal mossy fiber synapses. Brain Res 1320, 22-27.

7. Watanabe M, Tamano H, Kikuchi $\mathrm{T}$ et al. (2010) Susceptibility to stress in young rats after 2-week zinc deprivation. Neurochem Int 56, 410-416.

8. Sowa-Kucma M, Legutko B, Szewczyk B et al. (2008) Antidepressant-like activity of zinc: further behavioral and molecular evidence. J Neural Transm 115, 1621-1628.

9. Takeda A \& Tamado H (2009) Insight into zinc signaling from dietary zinc deficiency. Brain Res Rev 62, 33-44.

10. Tamano H, Kan F, Kawamura M et al. (2009) Behavior in the forced swim test and neurochemical changes in the hippocampus in young rats after 2 -week zinc deprivation. Neurochem Int 55, 536-541.

11. Takeda A (2009) Behavior in the forced swim test and neurochemical changes in the hippocampus in young rats after 2-week zinc deprivation. Neurochem Int 55, 536-541.

12. Cichy A, Sowa-Kucma M, Legutko B et al. (2009) Zincinduced adaptive changes in NMDA/glutamatergic and serontonergic receptors. Pharmacol Rep 61, 1184-1191.

13. Barrondo S \& Salles J (2009) Allosteric modulation of 5-HT1A receptors by zinc: binding sites. Neuropharmacology 56, $455-462$.

14. Michel TM, Frangou S, Thiemeyer D et al. (2007) Evidence for oxidative stress in the frontal cortex in patients with recurrent depressive disorder - a post-mortem study. Psychiatry Res 151, 145-150.

15. Kaplan BJ, Field CJ, Crawford SG et al. (2007) Vitamins, minerals and mood. Psychol Bull 133, 747-760.

16. Marcellini F, Giuli C, Papa R et al. (2006) Zinc status, psychological and nutritional assessment in old people recruited in five European studies: Zincage study. Biogerontology 7, 339-345.

17. Siwek MS, Wrobel A, Dudek D et al. (2005) The role of zinc in the pathogenesis and treatment of affective disorders. Psychiatr Pol 39, 899-909.
18. Bodnor LM \& Wisner KL (2005) Nutrition and depression: implications for improving mental health among childbearing aged women. Biol Psychiatry 58, 679-685.

19. Maes M, de Vos N, Demedts P et al. (1999) Lower serum zinc in major depression in relation to changes in serum acute phase proteins. J Affect Disord 56, 189-194.

20. Maes M, Vandoolaeghe E, Neels H et al. (1997) Lower serum zinc in major depression is a sensitive marker of treatment resistance and of the immune/inflammatory response in the illness. Soc Biol Psychiatry 42, 349-358.

21. Siwek M, Dudek D, Paul IA et al. (2009) Zinc supplementation augments efficacy of imipramine in treatment resistant patients. J Affect Disord 118, 187-195.

22. Walsh WJ, Isaacson HR, Rehman F et al. (1997) Elevated blood copper/zinc ratios in assaultive young males. Physiol Behav 62, 327-329.

23. Little KY, Castellanos X, Humphries LL et al. (1989) Altered zinc metabolism in mood disorder patients. Biol Psychiatry 26, 646-648.

24. Hanson CR, Malecha M, Mackenzie TB et al. (1982) Copper and zinc deficiencies in association with depression and neurological findings. Biol Psychiatry 18, 395-401.

25. Maes M, Neels H, Demedts P et al. (1997) Lower serum zinc in major depression is a sensitive marker. Biol Psychiatry 42, 349-353.

26. Levenson CW (2006) Zinc: the new antidepressant? Nutr $\operatorname{Rev}$ 64, 39-42.

27. Hwang JY, Lee SE, Kim SH et al. (2010) Psychological distress is associated with inadequate dietary intake in Vietnamese marriage immigrant women in Korea. $J$ Am Diet Assoc 110, 779-785.

28. Sawada T \& Yokoi K (2010) Effect of zinc supplementation on mood states in young women: a pilot study. Eur J Clin Nutr 64, 331-333.

29. Seiler WO (1999) Nutritional status in ill elderly subjects. Z Gerontol Geriatr 32, 7-11.

30. Haase H, Mocchegiani E \& Rink L (2006) Correlation between zinc status and immune function in the elderly. Biogerontology 7, 421-428.

31. Seiler WO, Itin P \& Stahelin HB (2002) Zinc deficiency, a problem of old age frequently not recognised. Ernahrungsschau 49, 260.

32. Rybka J, Kedziora-Kornatowska K, Kedziora J et al. (2009) Immunosenescence and late life depression. Cent Eur J Immunol 34, 271-275.

33. Maes M, de Vos N, Wauters A et al. (1999) Inflammatory markers in younger vs elderly normal volunteers. J Psychiatr Res 33, 397-405.

34. Reichies FM, Felsenberg D, Gessner R et al. (1998) Age and dementia effect on neuropsychological test performance in very old age-influence of risk factors for dementia. J Neural Transm 54, 69-76.

35. Drewnowski A \& Shulz JM (2001) Impact of aging on eating behaviour, food choices, nutrition and health status. J Nutr Health Aging 5, 75-79.

36. CidRuzafa J, Caulfield LE, Barron Y et al. (1999) Nutrient intakes and adequacy among an older population on the eastern shore of Maryland. J Am Diet Assoc 99, 546-571.

37. Kant AK \& Schatzkin A (1999) Relation of age and self reported medical condition status with dietary nutrient intake in the US population. J Am Coll Nutr 18, 69-76.

38. Webb KL, Schofield WN, Lazerus R et al. (1999) Prevalence and socio-demographic predictors of dietary goal attainment in an older population. Aust NZ J Public Health 23, 578-584

39. Cole MG \& Dendukuri N (2003) Risk factors for depression among elderly community subjects: a systematic review and meta-analysis. Am J Psychiatry 160, 1147-1156. 
40. Simpson EEA, McConville C, Rae G et al. (2008) Salivary cortisol, stress and mood in healthy older adults: the Zenith Study. Biol Psychol 78, 1-9.

41. Ostir GV, Ottenbacher KJ \& Markides KS (2004) Onset of frailty in older adults and the protective role of positive affect. Psychol Aging 19, 402-408.

42. Goh LY, Vitry AI, Semple SJ et al. (2009) Self-medication with over-the-counter drugs and complementary medications in South Australia's elderly population. BMC Comple Alt Med 9, 42.

43. World Health Organization (1995) Physical Status: The Use and Interpretation of Anthropometry. Report of a WHO Expert Committee. WHO Technical Report Series no. 854. Geneva: WHO.

44. Folstein MF, Folstein E \& McHugh PR (1975) Mini Mental State: a practical method for grading the cognitive state of patients for the clinician. J Psychiatr Res 12, 189-198.

45. Yesavage JA, Brink TL, Rose TL et al. (1983) Development and validation of a geriatric depression screening scale: a preliminary report. J Psychiatr Res 17, 37-49.

46. Almeida OP \& Almeida SA (1999) Short versions of the geriatric depression scale: a study of their validity for the diagnosis of a major depressive episode according to ICD-10 and DSM IV. Int J Geriatr Psychiatry 14, 858-865.

47. Polito A, Meunier N, Andriollo-Sanchez M et al. (2005) Screening and recruitment procedure of late-middle aged and older subjects. Eur J Clin Nutr 59, S8-S12.

48. Gibson RS (2005) Principles of Nutritional Assessment, 2nd ed. New York: Oxford University Press.

49. Miller LV, Krebs NF \& Hambridge MK (2000) Development of a compartmental model of human zinc metabolism: identifiability and multiple studies analyses. Am J Physiol Regul Intergr Comp Physiol 279, R11671-R11684.

50. Anriollo-Sanchez M, Hininger-Favier I, Meunier N et al. (2005) Zinc intake and status in middle-aged and older European Subjects: the Zenith study. Eur J Clin Nutr 59, S31-S36.

51. Polito A, Intorre F, Andriollo-Sanchez M et al. (2005) Estimation of intake and status of vitamin A, vitamin $\mathrm{E}$ and folate in older European adults: the Zenith study. Eur J Clin Nutr 59, S42-S47.

52. Watson D, Clarke LA \& Tellegen A (1988) Development and validation of brief measures of positive and negative affect: the PANAS scale. J Pers Soc Psychol 47, 1063-1070.

53. Watson D \& Tellegen A (1985) Towards a consensual structure of mood. Psychol Bull 98, 219-235.

54. Watson D \& Clark LA (1992) On traits and temperament: general and specific factors of emotional experience and their relation to the five factor model. J Pers 60, 441-476.

55. Williams E, Stewart-Knox B, Helander A et al. (2006) Associations between whole-blood serotonin and subjective mood in healthy male volunteers. Biol Psychol 71, 171-174.

56. Duffy M, Stewart-Knox B, McConville C et al. (2006) The relationship between whole-blood serotonin and subjective mood in apparently healthy postmenopausal women. Biol Psychol 73, 165-168.

57. Watson D \& Walker LM (1996) The long term stability and predictive validity of trait measures of affect. $J$ Pers Soc Psychol 70, 567-577.

58. Erdfelder E, Faul F \& Buchner A (1996) GPOWER: a general power analysis program. Behav Res Methods Instrum Comput 28, 1-11.

59. Simpson EEA, O'Connor JM, Livingstone MBE et al. (2005) Health and lifestyle characteristics of older European adults: the Zenith study. Eur J Clin Nutr 59, S13-S21.

60. Maylor EA, Simpson EEA, Secker DL et al. (2006) Effects of zinc supplementation on cognitive function in healthy middle-aged and older adults: the Zenith study. Br J Nutr 96, 752-760.

61. McConville C, Simpson EEA, Rae G et al. (2005) Positive and negative mood in the elderly: the Zenith study. Eur J Clin Nutr 59, S22-S25.

62. Hill RD, Van Boxtel MPJ, Ponds R et al. (2005) Positive affect and its relationship to free recall memory performance in a sample of older Dutch adults from the Maastricht aging study. Int J Geriatr Psychiatry 20, 429-435. 